Article

\title{
Soft Magnetic Properties of High-Entropy Fe-Co-Ni-Cr-Al-Si Thin Films
}

\author{
Pei-Chung Lin ${ }^{1}$, Chun-Yang Cheng ${ }^{1}$, Jien-Wei Yeh ${ }^{1, *}$ and Tsung-Shune Chin ${ }^{1,2}$ \\ 1 Department of Materials Science and Engineering, National Tsing Hua University, Hsinchu 30013, Taiwan; \\ jconcpfan@jcontaiwan.com (P.-C.L.); lj760320@hotmail.com (C.-Y.C.); tsc098@gmail.com (T.-S.C.) \\ 2 Department of Materials Science and Engineering, Feng Chia University, Taichung 40724, Taiwan \\ * Correspondence: jwyeh@mx.nthu.edu.tw; Tel.: +886-35-719-558
}

Academic Editors: Kevin H. Knuth and Adom Giffin

Received: 20 July 2016; Accepted: 16 August 2016; Published: 18 August 2016

\begin{abstract}
Soft magnetic properties of Fe-Co-Ni-Al-Cr-Si thin films were studied. As-deposited Fe-Co-Ni-Al-Cr-Si nano-grained thin films showing no magnetic anisotropy were subjected to field-annealing at different temperatures to induce magnetic anisotropy. Optimized magnetic and electrical properties of Fe-Co-Ni-Al-Cr-Si films annealed at $200{ }^{\circ} \mathrm{C}$ are saturation magnetization $9.13 \times 10^{5} \mathrm{~A} / \mathrm{m}$, coercivity $79.6 \mathrm{~A} / \mathrm{m}$, out-of-plane uniaxial anisotropy field $1.59 \times 10^{3} \mathrm{~A} / \mathrm{m}$, and electrical resistivity $3.75 \mu \Omega \cdot \mathrm{m}$. Based on these excellent properties, we employed such films to fabricate magnetic thin film inductor. The performance of the high entropy alloy thin film inductors is superior to that of air core inductor.
\end{abstract}

Keywords: high-entropy alloys; magnetic sputtering; thin films; magnetic property; electrical resistivity

\section{Introduction}

Conventional design of a thin film inductor is an air-core spiral. However, two disadvantages pronouncedly degrade the performance of air-core spiral in high working frequency. The first is parasitic coupling effect arising from the silicon substrate, and the second is the incompatibility with manufacturing processes for semiconductor-magnetic integrated circuits. The natural ferromagnetic resonance frequency $\left(f_{\mathrm{FMR}}\right)$ for a magnetic thin film in zero applied field, assuming pure rotation, is proportional to the saturation magnetization $\left(\mathrm{M}_{\mathrm{s}}\right)$ and the anisotropy field $\left(\mathrm{H}_{\mathrm{k}}\right)$ [1]. For a magnetic thin film inductor, the higher $\mathrm{M}_{\mathrm{s}}$ and $\mathrm{H}_{\mathrm{k}}$, the higher $f_{\mathrm{FMR}}$ and the better the performance at high working frequency conditions. The requirement of thicker magnetic thin films is essential to reduce the reluctance of the magnetic circuit and to increase device impedance. Simultaneously, an increased thickness results in high eddy current loss, and degraded quality factor of the devices [2]. Eddy current loss is inversely proportional to electrical resistivity $(\rho)$ [2]. High $\rho$ efficiently decreases eddy current loss and increases the quality factor of the devices. Besides, processing temperature can be several hundred degrees in Celsius, structure and property stability is important to keep the performance well after processing. In brief, magnetic thin films are considered as the potential candidate for thin-film inductors with an aim to improve their $\mathrm{M}_{\mathrm{s}}, \mathrm{H}_{\mathrm{k}}, \rho$, and also compatibility with semiconductor manufacturing processes. Therefore, tremendous efforts have been devoted to developing better magnetic thin films over past decades [3-19].

High-entropy alloys (HEAs) have been defined as those having at least five major metallic elements in which each has an atomic percentage between 5\% and 35\% since 2004 [20]. HEAs are also known with their tendency to have inherently high electrical resistivity and structure stability due to severe lattice distortion and sluggish diffusion [21-23]. In consideration of these merits, the present study designed the HEA Fe ${ }_{40} \mathrm{Co}_{35} \mathrm{Ni}_{5} \mathrm{Al}_{5} \mathrm{Cr}_{5} \mathrm{Si}_{10}$ with high saturation magnetization $9.5 \times 10^{5} \mathrm{~A} / \mathrm{m}$ in 
the as-cast state. The target made thereof was used for fabricating nano-structured magnetic thin film by magnetron sputtering. The variations of magnetic and electrical properties with field-annealing at different temperatures were investigated. Optimized magnetic and electrical properties of the $\mathrm{Fe}-\mathrm{Co}-\mathrm{Ni}$-Al-Cr-Si thin films were determined. On the basis of this optimization, standard VLSI process was employed to fabricate the magnetic thin film inductor to evaluate its inductance and quality factor ( $Q$ factor). Improved performances on inductance and $Q$ factor were expected.

\section{Experimental Procedures}

The sputtering target of $\mathrm{Fe}_{40} \mathrm{Co}_{35} \mathrm{Ni}_{5} \mathrm{Al}_{5} \mathrm{Cr}_{5} \mathrm{Si}_{10}$ was prepared with $\mathrm{Fe}, \mathrm{Co}, \mathrm{Ni}, \mathrm{Al}, \mathrm{Cr}$, and Si elemental raw materials (purity $>99.9 \%$ ) via vacuum arc-melting in a water-cooled crucible. The melting and solidification were repeated at least five times to ensure the chemical homogeneity. The solidified slab was cut into a disc with a diameter of 2 inch. It was then lathed and polished. $\mathrm{N}$-type silicon substrate with $200 \mathrm{~nm}$-thick $\mathrm{SiO}_{\mathrm{x}}$ layer was selected for the deposition of thin films. The deposition method was rf magnetron sputtering operated at a target power of $53 \mathrm{~W}$, under a base pressure better than $9 \times 10^{-6}$ Torr and a working pressure at $5 \times 10^{-3}$ Torr fixed with an argon gas flow of $18 \mathrm{sccm}$. The sample was rotated with $10 \mathrm{rpm}$ during sputtering and deposition rate was $12.5 \mathrm{~nm} / \mathrm{min}$. In order to induce magnetic anisotropy, the as-deposited samples were subjected to field-annealing at temperatures $100^{\circ} \mathrm{C}, 200^{\circ} \mathrm{C}, 300^{\circ} \mathrm{C}, 400^{\circ} \mathrm{C}$, and $500^{\circ} \mathrm{C}$, respectively for one hour under a magnetic field of $7.96 \times 104 \mathrm{~A} / \mathrm{m}$ applied parallel to the film plane.

Chemical composition of Fe-Co-Ni-Al-Cr-Si thin films was analyzed using an electron probe microanalyzer (EPMA, JAX-8800, JEOL, Peabody, MA, USA). The results confirmed that the film compositions were very close to that of $\mathrm{Fe}_{40} \mathrm{CO}_{35} \mathrm{Ni}_{5} \mathrm{Al}_{5} \mathrm{Cr}_{5} \mathrm{Si}_{10}$. The crystallographic structures of thin films were characterized utilizing a glancing incident angle X-ray diffractometer (GIAXRD, MXP18X, MAC Science, Tokyo, Japan) with $\mathrm{Cu} K \alpha$ radiation at $40 \mathrm{kV}, 150 \mathrm{~mA}$ and at the incident angle of $0.5^{\circ}$. Film thickness fixed at $250 \mathrm{~nm}$ was measured with an atomic force microscope (AFM, Model: Dimension ICON, Bruker, Billerica, MA, USA). A vibration sample magnetometer (VSM) was used to measure magnetization curves, from which the characteristic magnetic properties could be determined. Electrical resistivity was measured using a four-point probe measurement system (Keithley Model 224, Tektronix, Beaverton, OR, USA).

Spiral-type planar Fe-Co-Ni-Al-Cr-Si inductors were fabricated using standard VLSI processes. The planar inductor was based on the structure presented by Yamaguchi et al. [24]. The inductor consisted of four turning spiral coils. The spiral coils were $0.5 \mu \mathrm{m}$ thick, $13 \mu \mathrm{m}$ wide, and $20 \mu \mathrm{m}$ apart. In order to obtain uniaxial anisotropy, inductors were field-annealed at $200{ }^{\circ} \mathrm{C}$ for one hour in a vacuum better than $5 \times 10^{-6}$ Torr. After this thermal treatment, their inductance and $Q$ factor values were subsequently measured by the distributed parameter method employing a network analyzer HP $8610 \mathrm{C}$ using the microstrip line with an impedance of $50 \Omega$.

\section{Results and Discussion}

\subsection{Microstructure Identification of Fe-Co-Ni-Al-Cr-Si Thin Films}

Figure 1 shows the XRD patterns and Scherrer grain sizes of Fe-Co-Ni-Cr-Al-Si thin films at the as-deposited and post-annealing states. From Figure 1a, as-deposited films display the simple BCC structure. The BCC structure remains unchanged even after 1-h annealing at $400{ }^{\circ} \mathrm{C}$. The structure transforms to partially ordered BCC with the evidence of a small peak at around $30^{\circ}$ after 1-h annealing at $500{ }^{\circ} \mathrm{C}$. Nonetheless, no other structures, such as silicides, form in the films having $10 \mathrm{at} \% \mathrm{Si}$. This indicates that thermal stability of the BCC solid-solution phase with multiple elements is high. Such a stability is in fact enhanced by high entropy effect [22]. In Figure 1b, the average grain size, around $7.1 \mathrm{~nm}$, is almost identical for all states. This suggests that grain coarsening is highly suppressed as a result of severe lattice distortion and sluggish diffusion [25-27]. 

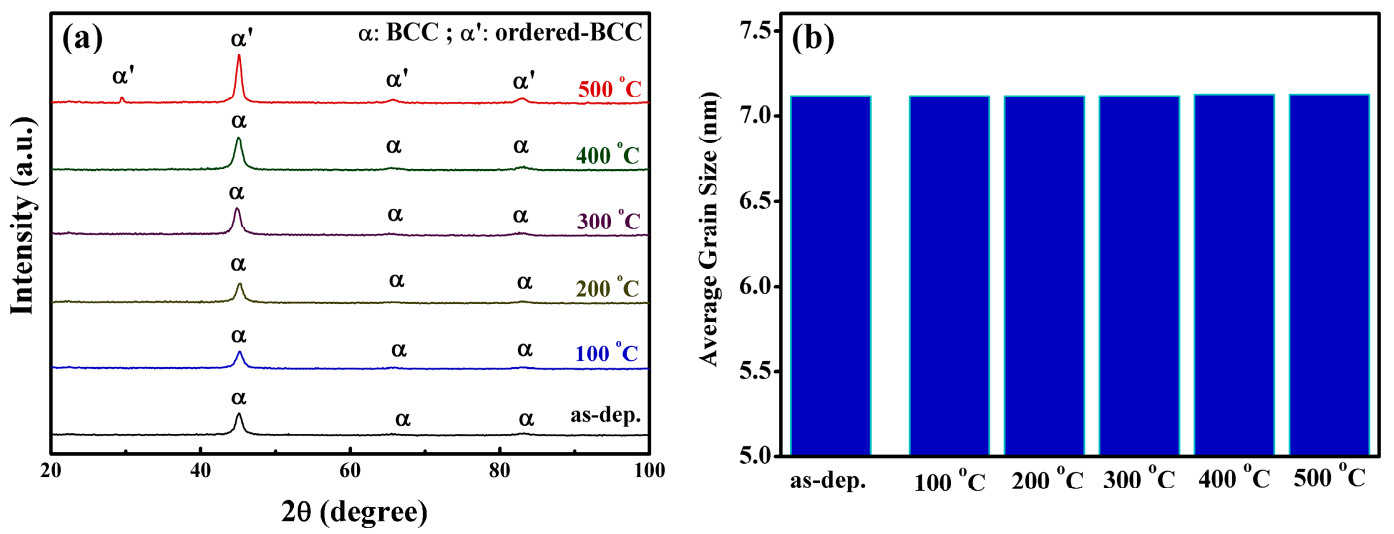

Figure 1. (a) XRD patterns of as-deposited Fe-Co-Ni-Cr-Al-Si films and those field-annealed at temperatures shown; (b) average grain size versus annealing temperatures.

\subsection{Magnetic Properties of Fe-Co-Ni-Al-Cr-Si Thin Films}

Figure 2 shows hysteresis loops of the as-deposited and post-annealed Fe-Co-Ni-Cr-Al-Si thin films. No magnetic anisotropy is observed in the hysteresis loop of as-deposited film. The corresponding saturation magnetization $\left(\mathrm{M}_{\mathrm{S}}\right)$ and coervicity $\left(\mathrm{H}_{\mathrm{c}}\right)$ are $7.98 \times 10^{5} \mathrm{~A} / \mathrm{m}$ and $1.83 \times 10^{3} \mathrm{~A} / \mathrm{m}$, respectively. However, magnetic anisotropy is induced by field-annealing at $100{ }^{\circ} \mathrm{C}-400{ }^{\circ} \mathrm{C}$. Magnetic anisotropy becomes insignificant after annealing at $500{ }^{\circ} \mathrm{C}$. The formation of ordered BCC phase at $500{ }^{\circ} \mathrm{C}$ (Figure 1) is thought to be responsible for this phenomenon. Chikazumi scrutinized the variation of magnetic anisotropy in $\mathrm{Fe}-\mathrm{Ni}$ alloys via field-annealing [28]. $\mathrm{He}$ found that the magnetic anisotropy of Fe-Ni alloys becomes less pronounced after annealing at $500{ }^{\circ} \mathrm{C}$. The deterioration of magnetic anisotropy was attributed to the formation of ordered $\mathrm{Fe}_{3} \mathrm{Ni}$ phase [28].

Figure 3 shows the saturation magnetization $\left(\mathrm{M}_{\mathrm{s}}\right)$, coercivity at hard axis $\left({ }_{\mathrm{h}} \mathrm{H}_{\mathrm{c}}\right)$, and coercivity at easy axis $\left(\mathrm{e}_{\mathrm{c}}\right)$ of Fe-Co-Ni-Cr-Al-Si films versus field-annealing temperature. The $\mathrm{M}_{\mathrm{s}}$ increases with increasing annealing temperature and reaches the maximum value of $10.8 \times 10^{5} \mathrm{~A} / \mathrm{m}$. It is found that present $\mathrm{M}_{\mathrm{s}}$ values are comparable to those reported in literature $[5,6,8]$. The magnetic anisotropy takes place under field-annealing at $100{ }^{\circ} \mathrm{C}$ and corresponding ${ }_{\mathrm{h}} \mathrm{H}_{\mathrm{C}}$ is $159 \mathrm{~A} / \mathrm{m}$, being one order reduced from the as-deposited value. With increasing annealing temperature from $100{ }^{\circ} \mathrm{C}$ to $300{ }^{\circ} \mathrm{C},{ }_{h} \mathrm{H}_{\mathrm{C}}$ value is further decreased to $79.6 \mathrm{~A} / \mathrm{m}$ at $200{ }^{\circ} \mathrm{C}$ and then increases to $135 \mathrm{~A} / \mathrm{m}$ at $300{ }^{\circ} \mathrm{C}$. It can be seen that ${ }_{\mathrm{h}} \mathrm{H}_{\mathrm{C}}$ value drastically increases when annealing temperature exceeds $400{ }^{\circ} \mathrm{C}$. The variation trend of $\mathrm{H}_{\mathrm{c}}$ is akin to that of ${ }_{\mathrm{h}} \mathrm{H}_{\mathrm{c}}$ though the value is much larger. Figure 3 also depicts that optimized soft magnetic properties of a minimum ${ }_{\mathrm{h}} \mathrm{H}_{\mathrm{c}}$ of $79.6 \mathrm{~A} / \mathrm{m}$ and a high $\mathrm{M}_{\mathrm{s}}$ of $9.13 \times 10^{5} \mathrm{~A} / \mathrm{m}$ can be attained after field-annealing at $200{ }^{\circ} \mathrm{C}$. In addition, the anisotropy field $\left(\mathrm{H}_{\mathrm{k}}\right) 1.59 \times 10^{3} \mathrm{~A} / \mathrm{m}$ is extracted from the field of magnetic saturation along the hard-axis in Figure 3c. The corresponding uniaxial anisotropy constant, $K_{u}$ is thus estimated to be $912 \mathrm{~J} / \mathrm{m}^{3}[29,30]$ which is higher than those of permalloy or mumetal [31-34]. Such magnetic properties are in fact very promising as compared to those reported in literature [5-8]. 

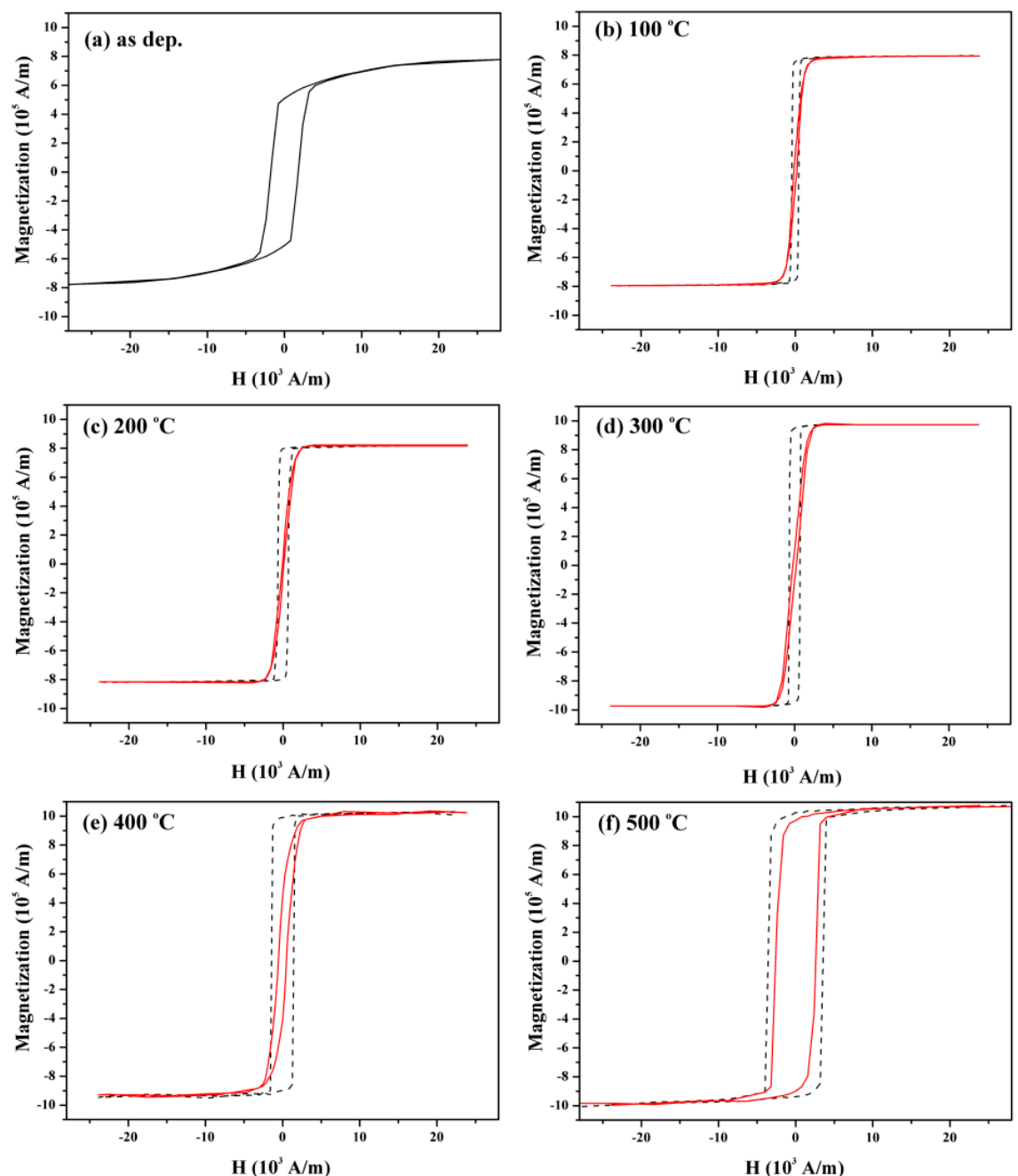

Figure 2. Hysteresis loops of the Fe-Co-Ni-Cr-Al-Si thin films: (a) as-deposited, and those field-annealed at (b) $100{ }^{\circ} \mathrm{C}$; (c) $200{ }^{\circ} \mathrm{C}$; (d) $300{ }^{\circ} \mathrm{C}$; (e) $400{ }^{\circ} \mathrm{C}$; and (f) $500{ }^{\circ} \mathrm{C}$. Black dashed and red solid curves represent easy axis (in-plane) and hard axis (out-of-plane), respectively.

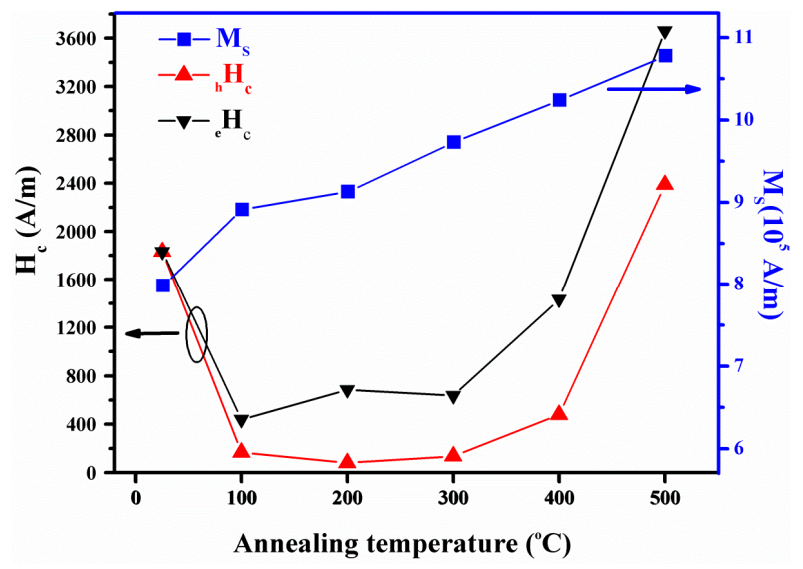

Figure 3. The saturation magnetization $\left(\mathrm{M}_{\mathrm{S}}\right)$, coercivity at hard axis $\left({ }_{h} \mathrm{H}_{\mathrm{C}}\right)$ and coercivity at easy axis $\left(\mathrm{e}_{\mathrm{C}}\right)$ of $\mathrm{Fe}-\mathrm{Co}-\mathrm{Ni}-\mathrm{Cr}-\mathrm{Al}-\mathrm{Si}$ thin films versus field-annealing temperature. These values are extracted from Figure 2. 


\subsection{Electrical Resistivity of Fe-Co-Ni-Al-Cr-Si Thin Films}

Electrical resistivity $(\rho)$ of $\mathrm{Fe}-\mathrm{Co}-\mathrm{Ni}-\mathrm{Cr}-\mathrm{Al}-\mathrm{Si}$ thin films versus field-annealing temperature is shown in Figure 4. By and large, electrical resistivity $(\rho)$ decreases from $4.36 \mu \Omega \cdot m$ of the as-deposited film to $1.40 \mu \Omega \cdot \mathrm{m}$ of the films field-annealed at $500{ }^{\circ} \mathrm{C}$. Electrical resistivity of films field-annealed at $200{ }^{\circ} \mathrm{C}$ remains as high as $3.75 \mu \Omega \cdot \mathrm{m}$. This is of most interest since the optimal magnetic properties are also achieved after the same annealing. This $\rho$ value is even higher than those of amorphous NdFeB ribbons $(3.15 \mu \Omega \cdot m)$ [29], and amorphous Al-Ti alloy films $(1.86-2.78 \mu \Omega \cdot m)[35,36]$. It is even higher than that of the N-type Si substrate $(\sim 1 \mu \Omega \cdot m)$. Such a high $\rho$ value is sufficient to reduce eddy current loss in applications under ultrahigh frequency conditions. Therefore, in combination with aforementioned optimal magnetic properties, $\mathrm{Fe}-\mathrm{Co}-\mathrm{Ni}-\mathrm{Cr}-\mathrm{Al}-\mathrm{Si}$ film becomes very promising in use as thin film inductors. Electrical resistance could be elucidated via the scattering of drifting electrons with scattering centers (e.g., defects) during electrical conduction processes [37]. The higher the degree of scattering, the higher the electrical resistance [37]. The observed high $\rho$ of Fe-Co-Ni-Cr-Al-Si thin films values could be attributed to several factors. First, eminent atomic size differences among the six elements and unbalanced bonds around an atom result in severe lattice distortion. These effects raise the degree of electron scattering with lattice [22]. Second, there are inherent highly-concentrated point defects in HEAs, resulting from multi-principal elements in a pseudo-unitary lattice (PUL) cell [38]. Third, a large number of grain boundaries due to nano-grained structure, which act as scattering centers [36]. Fourth, extra point- and line-defects introduced by sputtering deposition process. Note that the first and second factors could be regarded as intrinsic properties within HEAs, which allow HEAs to maintain high $\rho$ values irrespective of field-annealing. The third factor also sustains its contribution in $\rho$ value since the grain size remains almost unaltered after different annealing processes (Figure 1b). On the contrary, defects introduced by sputtering process are considerably diminished by annihilation processes during annealing. Higher temperature annealing would reduce the density of defects and thus decrease the $\rho$ value. This is also the reason why saturation magnetization $\mathrm{M}_{\mathrm{S}}$ and coercivity $\mathrm{H}_{\mathrm{c}}$ increase with annealing temperature as the magnetic dipoles and domain boundaries are less disturbed with reduced defects and thus have better dipole coupling and boundary movement, respectively. However, the formation of ordered BCC phase accounts for the greater decrease in $\rho$ value [37] and $\mathrm{H}_{\mathrm{c}}$ after annealing at $500{ }^{\circ} \mathrm{C}$.

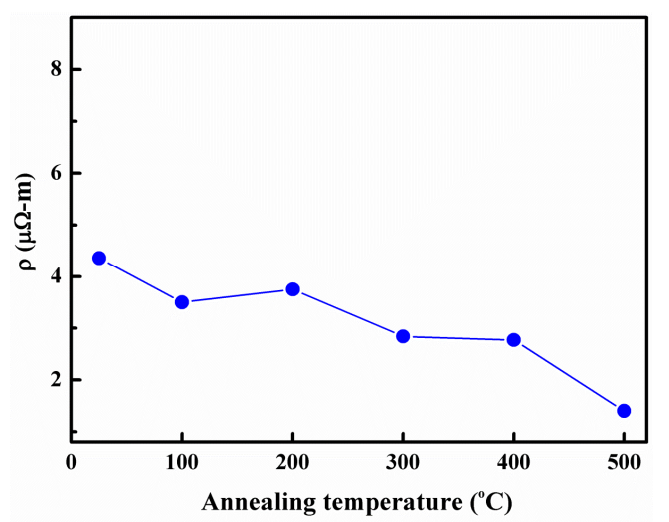

Figure 4. Electrical resistivity ( $\rho$ ) of Fe-Co-Ni-Cr-Al-Si thin films versus field-annealing temperature.

\subsection{Inductance and $Q$ Factor of the Fe-Co-Ni-Al-Cr-Si Magnetic Thin Film Inductor}

The magnetic Fe-Co-Ni-Cr-Al-Si thin film after field-annealing at $200{ }^{\circ} \mathrm{C}$ for one hour showing optimal magnetic properties of $\mathrm{M}_{\mathrm{s}} 9.13 \times 10^{5} \mathrm{~A} / \mathrm{m},{ }_{\mathrm{h}} \mathrm{H}_{\mathrm{c}} 79.6 \mathrm{~A} / \mathrm{m}$ and $\mathrm{H}_{\mathrm{k}} 1.59 \times 10^{3} \mathrm{~A} / \mathrm{m}$ corresponds to FMR frequency $1.34 \mathrm{GHz}$ as calculated using Landau-Lifshitz equation [1]. It also has a high electrical resistivity $(3.75 \mu \Omega \cdot \mathrm{m})$. Hence, it was chosen to fabricate thin film inductor and then evaluated. For the magnetic materials researched for such an application, their thin films almost have 
lower resistivity $(<2 \mu \Omega \cdot \mathrm{m})$ and thus higher eddy current loss [2] since the compositions are based on one or two major components even a significant amount of oxygen are incorporated into some compositions. As for the $\mathrm{M}_{\mathrm{s}}$ and $\mathrm{H}_{\mathrm{k}}$ values obtained after $200{ }^{\circ} \mathrm{C}$ field annealing, the calculated FMR frequency $1.34 \mathrm{GHz}$ is in the typical range although higher FMR frequency is pursued. Figure 5 shows (a) the optical image (plane view), (b) inductance, and (c) quality factor ( $Q$ factor) of the magnetic $\mathrm{Fe}-\mathrm{Co}-\mathrm{Ni}-\mathrm{Cr}-\mathrm{Al}-\mathrm{Si}$ thin film inductor as a function of frequency. From Figure $5 \mathrm{~b}$ the inductance of Fe-Co-Ni-Cr-Al-Si inductor has a maximum at $800 \mathrm{MHz}$ of $96 \mathrm{nH}$ which is $14 \%$ higher than that of air core inductor. While at $1.15 \mathrm{GHz}$, the inductance of the thin film inductor, $38.6 \mathrm{nH}$, is $31 \%$ higher than that of air-core inductor. In addition, Figure $5 \mathrm{c}$ depicts the maximum $\mathrm{Q}$ factor of $\mathrm{Fe}-\mathrm{Co}-\mathrm{Ni}-\mathrm{Cr}-\mathrm{Al}-\mathrm{Si}$ inductor at $800 \mathrm{MHz}, 2.02$, which is much significantly $89 \%$ larger than that of air core inductor. While at $1.05 \mathrm{GHz}$, the peak $\mathrm{Q}$ factor of thin film inductor- 0.868 - is $46 \%$ higher than that of air-core inductor. Both results demonstrate the excellent performance of the inductor fabricated with Fe-Co-Ni-Cr-Al-Si thin films. Moreover, these performances are comparable to those of other magnetic-based inductors, again indicating the Fe-Co-Ni-Cr-Al-Si thin film promising for the application in inductors [39-41].

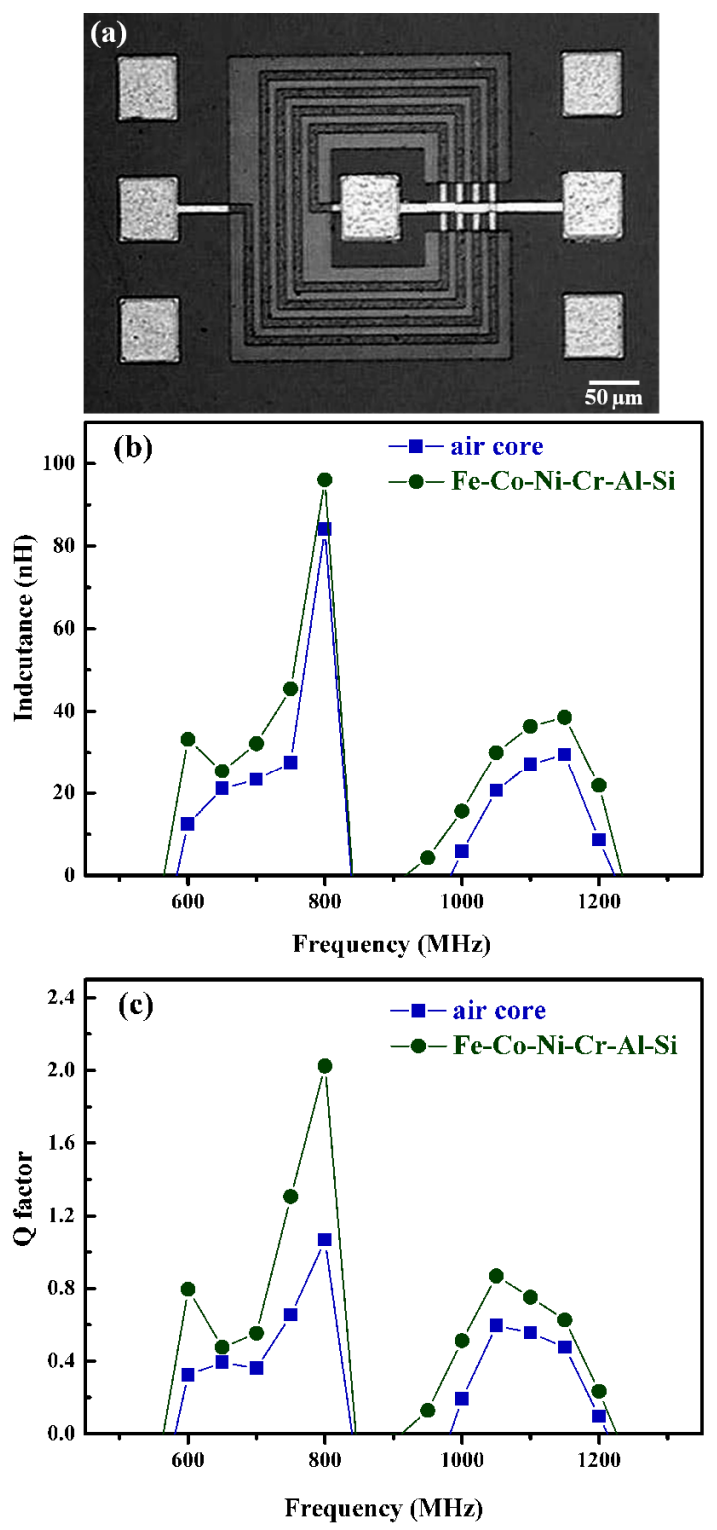

Figure 5. (a) The optical image (plane view); (b) inductance; and (c) quality factor (Q Factor) of the magnetic Fe-Co-Ni-Cr-Al-Si thin film inductors as a function of frequency. 
The variation of inductance and $\mathrm{Q}$ factors with frequency for both Fe-Co-Ni-Cr-Al-Si and air core inductors are quite akin. There are two abrupt drops near $800 \mathrm{MHz}$ and $1200 \mathrm{MHz}$ for the inductance and $Q$ factor of both thin film inductor and air core inductor. It is reasonable to attribute the two drops to the structure of inductors and not to the film itself. Insufficient large scales of inductor $\left(508 \times 508 \mu \mathrm{m}^{2}\right)$ and silicon substrate with a resistivity of $1 \mu \Omega \cdot \mathrm{m}$ cause leakage current to occur near $800 \mathrm{MHz}$ and $1.2 \mathrm{GHz}$.

\section{Conclusions}

High entropy Fe-Co-Ni-Cr-Al-Si thin films have been successfully fabricated to exhibit excellent soft magnetic properties. The thin film has simple BCC structure under as-deposited and post-annealing at $400{ }^{\circ} \mathrm{C}$ and below. An ordered BCC structure forms after annealing at $500{ }^{\circ} \mathrm{C}$. After field-annealing at different temperatures, the average grain sizes, $7.1 \mathrm{~nm}$, are almost unaltered as compared to the as-deposited one. The high thermal stability of nanostructured BCC solid solution phase is due to high entropy, severe-lattice distortion, and sluggish diffusion effects. The optimized magnetic properties of thin films obtained by field-annealing at $200{ }^{\circ} \mathrm{C}$ for one hour are $\mathrm{M}_{\mathrm{s}} 9.13 \times 10^{5} \mathrm{~A} / \mathrm{m},{ }_{\mathrm{h}} \mathrm{H}_{\mathrm{c}} 79.6 \mathrm{~A} / \mathrm{m}$ and $\mathrm{H}_{\mathrm{k}} 1.59 \times 10^{3} \mathrm{~A} / \mathrm{m}$, respectively. Electrical resistivity of the $200{ }^{\circ} \mathrm{C}$ annealed thin films is $3.75 \mu \Omega \cdot \mathrm{m}$. The inductance and $\mathrm{Q}$ factor of the thin films inductors made thereof is increased by $14 \%$ and $89 \%$ at $800 \mathrm{MHz}$, respectively, as compared with air core inductors. While at $1.15 \mathrm{GHz}$, the inductance of the thin film inductor is $31 \%$ higher, and at $1.05 \mathrm{GHz}$ the $\mathrm{Q}$ factor is $46 \%$ higher than that of air-core inductor. This justifies the excellence of Fe-Co-Ni-Cr-Al-Si thin films inductors. Most importantly, this study demonstrates that the merits of magnetic HEAs, including high resistivity and nanostructure stability, are very helpful for designing even better magnetic thin film inductors.

Acknowledgments: The authors thank the financial support from the Ministry of Science and Technology, Taiwan, under the Project No. NSC-95-2120-M-007-004.

Author Contributions: Jien-Wei Yeh and Tsung-Shune Chin conceived and designed the experiments; Pei-Chung Lin, Jien-Wei Yeh and Tsung-Shune Chin performed the experiments; Pei-Chung Lin, Chun-Yang Cheng, Jien-Wei Yeh and Tsung-Shune Chin analyzed the data; Jien-Wei Yeh and Tsung-Shune Chin contributed materials and analysis tools; Chun-Yang Cheng, Jien-Wei Yeh and Tsung-Shune Chin wrote the paper. All authors have read and approved the final manuscript.

Conflicts of Interest: The authors declare no conflict of interest.

\section{References}

1. Chikazumi, S. Physics of Magnetism; Wiley: New York, NY, USA, 1964.

2. Bozorth, R.M. Ferromagnetism; D. Van Nostrand Co.: Princeton, NJ, USA, 1951.

3. Chen, L.H.; Zhu, W.; Tiefel, T.H.; Jin, S.; van Dover, R.B.; Korenivski, V. Fe-Cr-Hf-N and Fe-Cr-Ta-N soft magnetic thin films. IEEE Trans. Magn. 1997, 33, 3811-3813. [CrossRef]

4. Jin, S.; Zhu, W.; Tiefel, T.H.; Korenivski, V.; van Dover, R.B.; Chen, L.H. Fe-Cr-N soft magnetic thin films. J. Appl. Phys. 1997, 81, 4042-4044. [CrossRef]

5. Lee, C.H.; Shin, D.H.; Ahn, D.H.; Nam, S.E.; Kim, H.J. Fabrication of thin film inductors using FeTaN soft magnetic films. J. Appl. Phys. 1999, 85, 4898-4900. [CrossRef]

6. Klemmer, T.J.; Ellis, K.A.; Chen, L.H.; van Dover, B.; Jin, S. Ultrahigh frequency permeability of sputtered Fe-Co-B thin films. J. Appl. Phys. 2000, 87, 830-833. [CrossRef]

7. Fergen, I.; Seemann, K.; von der Weth, A.; Schuppen, A. Soft ferromagnetic thin films for high frequency applications. J. Magn. Magn. Mater. 2002, 242, 146-151. [CrossRef]

8. Chen, L.H.; Chen, H.K.; Hsieh, C.T.; Shih, Y.H.; Chen, I.G.; Chen, S.Y.; Liu, H.P. Soft magnetic properties of Co-Fe-Zr-B-Al-O films. J. Appl. Phys. 2002, 91, 8450-8452. [CrossRef]

9. Chen, H.K.; Li, S.H.; Duh, J.G. Structure and soft magnetic properties of Fe-Co-Ni-based multicomponent thin films. J. Electron. Mater. 2005, 34, 1480-1483. [CrossRef] 
10. Aoqui, S.I.; Munakata, M. Uniaxial anisotropy field and crystalline structures of $(\mathrm{CoFe})-\left(\mathrm{SiO}_{2}\right)$ magnetic thin film for operating in the GHz frequency. Mater. Sci. Eng. A Struct. Mater. Prop. Microstruct. Process. 2005, 413, 550-554. [CrossRef]

11. Ha, N.D.; Phan, M.H.; Kim, C.O. Novel nanostructure and magnetic properties of Co-Fe-Hf-O films. Nanotechnology 2007, 18, 155705. [CrossRef]

12. Kuo, C.L.; Li, S.D.; Duh, J.G. Development and optimisation of FeCoHfN soft magnetic thin films with high-frequency characteristics. Appl. Surf. Sci. 2008, 254, 7417-7420. [CrossRef]

13. Liu, M.M.; Li, S.D.; Duh, J.G. High-Frequency Ferromagnetic Properties and Magnetic Domain Structures of FeNdBO Thin Films. J. Nanosci. Nanotechnol. 2009, 9, 836-839. [CrossRef] [PubMed]

14. Kuo, Y.M.; Li, S.D.; Duh, J.G. High-frequency ferromagnetic properties of multilayered $\mathrm{FeCoHfO/AlOx}$ films. Mater. Res. Bull. 2010, 45, 1916-1920. [CrossRef]

15. Huang, S.W.; Lai, Y.T.; Duh, J.G. Effects of the Hf content on the microstructure and magnetic properties of Co-Hf-Ta thin films. Appl. Surf. Sci. 2011, 257, 2042-2045. [CrossRef]

16. Chang, H.W.; Huang, Y.H.; Hsieh, C.C.; Shih, C.W.; Chang, W.C.; Xue, D.S. Study on the soft magnetic properties and high frequency characteristics of Co-M (M = Ti, Zr, and Hf) thin films. J. Appl. Phys. 2012, 111, 07A333. [CrossRef]

17. Chang, H.W.; Huang, Y.H.; Hsieh, C.C.; Shih, C.W.; Chang, W.C.; Xue, D.S. Magnetic properties and high frequency characteristic of obliquely sputtered $\mathrm{Co}-\mathrm{M}(\mathrm{M}=\mathrm{V}$ and $\mathrm{Nb})$ thin films. J. Alloys Compd. 2012, 539, 276-279. [CrossRef]

18. Chang, H.W.; Chuang, L.C.; Shih, C.W.; Chang, W.C.; Xue, D.S. Optimization of high frequency characteristics in Co-Ta thin films. J. Appl. Phys. 2014, 115, 17A312. [CrossRef]

19. Naoe, M.; Kobayashi, N.; Ohnuma, S.; Iwasa, T.; Arai, K.I.; Masumoto, H. Ultra-high resistive and anisotropic $\mathrm{CoPd}-\mathrm{CaF}_{2}$ nanogranular soft magnetic films prepared by tandem-sputtering deposition. J. Magn. Magn. Mater. 2015, 391, 213-222. [CrossRef]

20. Yeh, J.W.; Chen, S.K.; Lin, S.J.; Gan, J.Y.; Chin, T.S.; Shun, T.T.; Tsau, C.H.; Chang, S.Y. Nanostructured high-entropy alloys with multiple principal elements: Novel alloy design concepts and outcomes. Adv. Eng. Mater. 2004, 6, 299-303. [CrossRef]

21. Chou, H.P.; Chang, Y.S.; Chen, S.K.; Yeh, J.W. Microstructure, thermophysical and electrical properties in AlxCoCrFeNi $(0 \leq x \leq 2)$ high-entropy alloys. Mater. Sci. Eng. B 2009, 163, 184-189. [CrossRef]

22. Murty, B.S.; Yeh, J.W.; Ranganathan, S. High-Entropy Alloys; Butterworth-Heinemann: Boston, MA, USA, 2014.

23. Chen, S.K.; Kao, Y.F. Near-constant resistivity in 4.2-360 K in a B2 $\mathrm{Al}_{2.08} \mathrm{CoCrFeNi.} \mathrm{AIP} \mathrm{Adv.} \mathrm{2012,} 2,012111$. [CrossRef]

24. Yamaguchi, M.; Suezawa, K.; Takahashi, Y.; Arai, K.I.; Kikuchi, S.; Shimada, Y.; Tanabe, S.; Ito, K. Magnetic thin-film inductors for RF-integrated circuits. J. Magn. Magn. Mater. 2000, 215, 807-810. [CrossRef]

25. Lai, C.H.; Lin, S.J.; Yeh, J.W.; Chang, S.Y. Preparation and characterization of AlCrTaTiZr multi-element nitride coatings. Surf. Coat. Technol. 2006, 201, 3275-3280. [CrossRef]

26. Chang, H.W.; Huang, P.K.; Yeh, J.W.; Davison, A.; Tsau, C.H.; Yang, C.C. Influence of substrate bias, deposition temperature and post-deposition annealing on the structure and properties of multi-principal-component (AlCrMoSiTi)N coatings. Surf. Coat. Technol. 2008, 202, 3360-3366. [CrossRef]

27. Huang, P.K.; Yeh, J.W. Inhibition of grain coarsening up to 1000 degrees $\mathrm{C}$ in (AlCrNbSiTiV)N superhard coatings. Scr. Mater. 2010, 62, 105-108. [CrossRef]

28. Chikazumi, S. Ferromagneticf Properties and Superlattice Formation of Iron Nickel Alloys (II). J. Phys. Soc. Jpn. 1950, 5, 327-333. [CrossRef]

29. Wang, S.G.; Ong, C.K.; Li, Z.W. Thickness and angle dependence of the coercivity on highly uniaxial anisotropy FeTaN thin films. Phyica B 2004, 349, 129-135. [CrossRef]

30. Frey, H.; Khan, H.R. Handbook of Thin-Film Technology; Springer: Berlin/Heidelberg, Germany, 2015.

31. Fu, C.M.; Kao, P.C.; Tsai, M.S.; Hsu, H.S.; Yu, C.C.; Huang, J.C.A. Magnetic anisotropy of permalloy thin film on Mo stepped surface. J. Magn. Magn. Mater. 2002, 239, 17-21. [CrossRef]

32. Comstock, R.L. Introduction to Magnetism and Magnetic Recording; Wiley: New York, NY, USA, 1999.

33. Jiles, D.C. Introduction to Magnetism and Magnetic Materials; CRC Press: Boca Raton, FL, USA, 1998.

34. Liu, J.P.; Fullerton, E.; Gutfleisch, O.; Sellmyer, D.J. Nanoscale Magnetic Materials and Applications; Springer: Boston, MA, USA, 2009. 
35. Saito, T. Electrical resistivity and magnetic properties of Nd-Fe-B alloys produced by melt-spinning technique. J. Alloys Compd. 2010, 505, 23-28. [CrossRef]

36. Canulescu, S.; Borca, C.N.; Rechendorff, K.; Davidsdottir, S.; Almtoft, K.P.; Nielsen, L.P.; Schou, J. Optical and electrical properties of polycrystalline and amorphous Al-Ti thin films. Appl. Phys. Lett. 2016, 108, 141909. [CrossRef]

37. Hummel, R.E. Electronic Properties of Materials, 3rd ed.; Springer: New York, NY, USA, 2001.

38. Kao, Y.F.; Chen, S.K.; Chen, T.J.; Chu, P.C.; Yeh, J.W.; Lin, S.J. Electrical, magnetic, and Hall properties of AlxCoCrFeNi high-entropy alloys. J. Alloys Compd. 2011, 509, 1607-1614. [CrossRef]

39. Li, S.D.; Duh, J.G.; Liao, C.N. High-frequency ferromagnetic inductors covered by as-deposited FeCoAlO films with stress-induced uniaxial anisotropy. Thin Solid Films 2008, 516, 7748-7752. [CrossRef]

40. Davies, R.P.; Cheng, C.; Sturcken, N.; Bailey, W.E.; Shepard, K.L. Coupled inductors with crossed anisotropy $\mathrm{CoZrTa} / \mathrm{SiO}_{2}$ multilayer cores. IEEE Trans. Magn. 2013, 49, 4009-4012. [CrossRef]

41. Bechir, M.H.; Yaya, D.D.; Kahlouche, F.; Soultan, M.; Youssouf, K.; Capraro, S.; Chatelon, J.P.; Rousseau, J.J. Planar inductor equivalent circuit model taking into account magnetic permeability, loss tangent, skin and proximity effects versus frequency. Analog Integr. Circuits Process 2016, 88, 105-113. [CrossRef]

(C) 2016 by the authors; licensee MDPI, Basel, Switzerland. This article is an open access article distributed under the terms and conditions of the Creative Commons Attribution (CC-BY) license (http://creativecommons.org/licenses/by/4.0/). 